\title{
Investigations of castellated structures for ITER: the effect of castellation shaping and alignment on fuel retention and impurity deposition in gaps
}

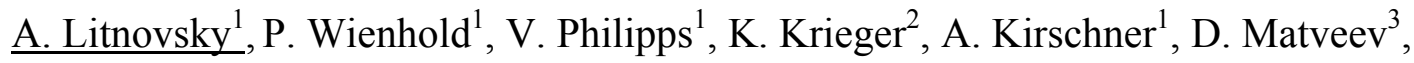 \\ D. Borodin ${ }^{1}$, G. Sergienko ${ }^{1}$, O. Schmitz ${ }^{1}$, A. Kreter ${ }^{1}$, U. Samm ${ }^{1}$, S.Richter ${ }^{4}$, U. Breuer ${ }^{5}$, \\ J. P. Gunn ${ }^{6}$, M. Komm ${ }^{7}$, Z. Pekarek ${ }^{8}$ and TEXTOR Team
}

${ }^{1}$ Institut für Energieforschung - Plasmaphysik, Forschungszentrum Jülich, Trilateral Euregio Cluster, Association EURATOM- FZ Jülich, D-52425 Jülich, Germany;

${ }^{2}$ Max-Planck-Institut für Plasmaphysik, D-85748, Garching, Germany;

${ }^{3}$ Ghent University, Trilateral Euregio Cluster, Rozier B-9000, Ghent, Belgium

${ }^{4}$ Gemeinschaftslabor für Elektronenmikroskopie, RWTH Aachen, D-52056, Aachen, Germany;

${ }^{5}$ Zentralabteilung für Chemische Analysen, Forschungszentrum Jülich, D-52425, Jülich,

Germany;

${ }^{6}$ Association Euratom-CEA, CEA/DSM/DRFC, Centre de Cadarache, 13108, Saint-Paul-Lez-Durance, France;

${ }^{7}$ Charles University in Prague, Faculty of Mathematics and Physics, Czech Republic.

\begin{abstract}
Castellation will be used in divertor and first wall components to provide thermomechanical stability of ITER. Radioactive fuel may be stored in the gaps of castellated structures representing the safety issue for ITER.

Castellated structures with different shapes were exposed in the SOL plasmas of TEXTOR to test an impact of cell shaping on impurity transport and fuel deposition in the gaps. After exposure the significant tungsten intermixing was detected in the deposits in the
\end{abstract}


gaps reaching 70 at. $\% \mathrm{~W}$ in the deposition layer. This will provide difficulties in cleaning the gaps in ITER. Poloidal gaps of shaped cells contained a factor of 3 less deuterium than those of rectangular cells. However, carbon deposition exhibited only marginal advantages of a new geometry. An amount of carbon found in toroidal gaps was comparable with that in poloidal gaps, calling for the further optimization of the cell geometry in both directions. Significant deposition at the bottom of gaps was measured: about $14 \%$ of the total $\mathrm{C}$ deposition in the poloidal gaps was detected at their bottom. These new findings may only partly and qualitively reproduced by modeling.

PACS: 52.55.Fa; 52.40.Hf; 52.25.Vy

JNM Keywords: Plasma-material interactions (P0500), Surface effects (S1300), Carbon (C0100).

Corresponding and presenting author: Dr. Andrey Litnovsky

Corresponding and presenting author address: Institut für Energieforschung - Plasmaphysik, Forschungszentrum Jülich, D-52425 Jülich, Germany

Corresponding and presenting author E-mail: a.litnovsky@,fz-juelich.de 


\section{Introduction}

First wall and divertor armor in ITER will be castellated by splitting them into the number of small-size cells. The main purpose of such a castellation is to maintain the thermomechanical stability of ITER under highly inhomogeneous thermal loads. There is a known concern that the radioactive tritium will be accumulated in the gaps of the castellation leading the undesirable fuel inventory there and representing safety issue for ITER. Therefore the dedicated experimental and theoretical studies of the fuel accumulation in the gaps are ongoing on several facilities worldwide [1-3]. Investigations of deposits on the gaps of castellated structures are important for the assessment of the feasibility of the cleaning of gaps, which might become necessary for continuation of ITER operation.

The dedicated research is ongoing in Forschungszentrum Jülich (Germany, EU) where the impurity transport into the gaps, fuel inventory there, melt layer formation and enhanced erosion of molten layer of the castellation and the cleaning of deposits in the gaps are being investigated both experimentally and theoretically [4-9]. In the recent experiment the tungsten test limiter with two different shapes of castellation was exposed in the SOL plasmas in TEXTOR. The aim of this experiment was to minimize the impurity and fuel transport to the gaps of castellated structures and their accumulation by introducing the new shape of castellation cells.

\section{Experimental}

Tungsten castellated limiter had the double roof form where the two types of castellated cells were situated: the conventional rectangular cells with dimensions $(10 \times 10 \times 15$ $\mathrm{mm})$ and the roof-like shaped cells with dimensions (10x10x12/15 mm). Each of the cells was mounted separately on the castellation holder. 
The limiter was introduced to TEXTOR using the limiter lock transport system [10] and exposed in the scrape-off layer (SOL) plasmas at the radial distance $\mathrm{R}=46.8 \mathrm{~cm}$ which is $0.8 \mathrm{~cm}$ further away from the Last Closest Flux Surface (LCFS). Sixteen identical neutral beam-heated discharges were made with the total plasma duration of 112 seconds. The plasma parameters in the vicinity of the test limiter were monitored using the fast probe, $\mathrm{W}, \mathrm{C}, \mathrm{H}$ spectroscopy measurements were made. The bulk temperature of the limiter $\sim 200^{\circ} \mathrm{C}-250^{\circ} \mathrm{C}$ as controlled with thermocouples, the surface temperature of the tungsten castellated top surface was monitored via optical pyrometer. In the end of exposure, there were problems with vertical plasma control causing plasma shifts towards the limiter, leading to the local excursions of the surface temperature of the castellation up to $1500^{\circ} \mathrm{C}$. Both castellated structures were exposed in the same plasma environment which was inferred from the dedicated $\mathrm{H} \alpha$ measurements.

The photograph of the limiter after exposure is shown on the figure 1. The nomenclature introduced earlier in [8] is remained. The shaped cells facing the s.c. ion-drift direction are marked with "i" -sign). In a full similarity the rectangular cells were facing an electron-drift direction, therefore they were assigned an "e" letter. There were 2 rows with 3 cells in the row for each shape of castellation. The rows were enumerated starting from the plasma-closest uppermost one. The cells were marked with letters "a" to "c" as it is shown on

Fig. 1. The gaps elongated along the toroidal field direction are referred as the toroidal gaps. Similarly the gaps aligned along the direction of the poloidal field are referred as poloidal ones.

\section{Post-exposure analyses}

After exposure the limiter was disassembled and each of the cells was visually inspected. The top plasma wetted surfaces were metallically shiny, whereas in all the gaps the 
deposition patterns were observed. Secondary Ion Mass-Spectrometry (SIMS) measurements were made on both toroidal and poloidal gaps, at the bottom of gaps (on the holder plate) and on the top surfaces. Double-beam ToF SIMS 4 facility was used, operating with Cs and O beams. The SIMS measurements were calibrated using DEKTAK stylus profiler. To investigate the total areal density both carbon and deuterium, the line-scans using the Nuclear Reaction Analyses (NRA) measurements were made on the side surfaces of both shaped and non-shaped cells utilizing $1.2 \mathrm{MeV}$ beam of ${ }^{3} \mathrm{He}$ ions. To investigate the carbon concentration with higher lateral resolution the Electron Probe MicroAnalysis measurements were made on toroidal and poloidal gaps just near to the NRA scans. To analyze carbon concentration an intensity of inner CKa electron emission was used.

\section{Results}

Tungsten intermixing in the deposits

Using the evaluation software from EPMA measurements it was possible to simulate the measured attenuation of the CKa emission and cross-correlate it with NRA and SIMS measurements which were insensitive to $\mathrm{W}$ intermixing. Such an evaluation was made for both toroidal and poloidal gaps. An example of the evaluation made on the poloidal gap is provided on the figure 2 . The $\mathrm{W}$ fraction on the deposit is very significant, reaching 70 at. $\%$ of $\mathrm{W}$ at the plasma-closest edge of the plasma-shadowed side of the gap. Such a strong intermixing will cause the significant problems of cleaning deposits in the gaps. The W fraction in the deposit sharply decreases with the depth of a gap rapidly reaching about 2 at. \% approximately $2 \mathrm{~mm}$ deeper in the gap. Remarkably, significantly lower concentration of $\mathrm{W}$ was obtained at toroidal gaps reaching around only 10 at. \%. at its maximum.

\section{Poloidal gaps}


The deposition patterns on the poloidal gaps of shaped and rectangular cells exhibit the remarkable differences: on the rectangular (non-shaped) cells on the gap side open to the plasma the very thin shiny net erosion zone followed by the net deposition zone deeper in the gap were detected in the full similarity with those found in the previous experiments with castellated limiters in TEXTOR $[4,7]$. On the contrary, only metallically shiny zone was observed on the plasma open sides of the shaped cells. The respective images of the poloidal gaps are provided on the figure 3. The dedicated measurements made on poloidal gaps of both geometries have revealed different deposition patterns for the shaped and non-shaped cells: for the non-shaped gaps the deposition pattern is much more peaked and reaching significantly higher maximum value than that for shaped cells. The typical deposition profiles for the shaped and non-shaped cells of poloidal gaps are either provided on figure 3 . The integration of the deposition profiles were made for both geometries of cells in order to get the total amount of carbon and deuterium deposited in the gaps. During this analyses all the data from NRA, SIMS/DEKTAK, and EPMA where thoroughly checked, so that the accuracy of this quantification is better than $20 \%$.

The results are briefly summarized in the table 1, part a. Significantly lower amount of D was found deposited on the gaps of shaped cells, than that of rectangular ones. The same time, the amount of carbon in the gaps of both geometries is quite comparable, the rectangular gaps contain only about $30 \%$ more carbon. This outlines a need for the further optimization of the cell shapes. The overall $\mathrm{D} / \mathrm{C}$ ratio is rather small, not exceeding 0.05 which is due to the thermal excursions during the exposure.

\section{Toroidal gaps}

Similar measurements were made on toroidal gaps for both geometries of cells and for both rows of castellation. However, the quantification of the deposition of carbon and deuterium 
appeared to be very time-taking process based on the analyses of the complicated 2D deposition patterns on the toroidal gaps. Results are briefly outlined in the table 1 part $b$. Large difference in total amount of $\mathrm{C}$ and $\mathrm{D}$ was observed depending on the side of the gap: right or left from the magnetic field direction (fig. 1). Interestingly, such a difference was absolutely independent on the cell shaping. Moreover, the deposition patterns on the toroidal cells located at the left from toroidal magnetic field direction were very similar for shaped and non-shaped cells and were drastically different form those profiles obtained on the side at the right to the $\mathrm{B}_{\mathrm{T}}$ direction. These observations may outline that the misalignment of the gaps with respect to magnetic field direction could not be the major process leading to the observed deposition in these gaps. The most probable reason is the local shadowing of one side of toroidal gaps due to large gyroradii of the main plasma/impurity ions compared to the gap width. Indeed, the dedicated calculations provided that the typical Larmor radii for the main plasma and impurity ions are of order of $1.5-2 \mathrm{~mm}$ whereas the gap size in our experiment is only $0.5 \mathrm{~mm}$. This would mean that in ITER the gyroradii and the corresponding gap width may be the decisive parameters largely influencing the deposition patterns in the gaps. This may also provide an additional tool of minimizing the impurity transport and fuel accumulation in these gaps by an additional shaping of these cells. (I will probably remove this part, since it is a bit speculative, AL)

\section{Comparison of poloidal and toroidal gaps}

The comparative analyses of overall $\mathrm{C}$ and $\mathrm{D}$ amounts in poloidal and toroidal gaps is presented in the table 1 part $\mathrm{c}$. As it can be seen, the toroidal gaps contain the comparable amount of deuterium, as poloidal ones. An amount of carbon stored in toroidal gaps is even higher than that in poloidal gaps for any of geometries studied. This explicitly means that the toroidal gaps cannot be ignored while assessing the transport and accumulation in gaps. 
Moreover, the data calls for dedicated studies of the deposits in the toroidal gaps and using the direct measurements rather than extrapolation of the results form poloidal gaps on toroidal ones.

\section{Top surfaces}

After exposure the top plasma-wetted surfaces of the castellation cells were metallically shiny exhibiting the area of net erosion, which was afterwards confirmed by the dedicated SIMS measurements. This fact together with measurements in gaps demonstrates that although the limiter was exposed under erosion-dominated conditions, there were deposition-dominated conditions in the gaps. The measurements on the top surfaces brought another worrying result. On the shaped cells because of the geometry of shaping an area of the local shadowing from the plasma was created. SIMS measurements with DEKTAK calibration have detected the carbon deposits with the thickness of up to $40 \mathrm{~nm}$ on these shadowed top surfaces. These carbon deposits were growing presumably throughout the entire exposure time due to $\mathrm{C}$ transport into the shadowed area. However, these deposits were afterwards completely covered with $150 \mathrm{~nm}$-thick layer of $\mathrm{W}$, having pure metallic appearance and not resembling visually from the neighboring eroded tungsten area. The reason for such a massive $\mathrm{W}$ deposition is presumably in the three events happened at the end of exposure when plasma

was heavily shifted on the limiter leading to the enhanced erosion of the tungsten limiter components. Such a "protective" metal covering if occurred in ITER during e.q. transient effects will make the cleaning of deposits on the tops of castellations impossible.

\section{Deposition at the bottom of the gaps}

The deposition at the bottom of the gaps was detected on the holder of the castellated samples. The dedicated calibrated SIMS measurements revealed up to $200 \mathrm{~nm}$-thick deposits. No 
tungsten intermixing has occurred in the deposits. No anisotropy in poloidal or toroidal directions was observed, possibly pointing out to the neutral origin of the deposition. An estimate of $\mathrm{C}$ amount deposited at the bottom and its comparison with the values measured on both poloidal and toroidal gaps is evidencing that impurity transport and fuel accumulation at the bottom of gaps rather significant: about $14 \%$ of total amount of $\mathrm{C}$ deposited in the poloidal gaps were detected at their bottom surfaces. Interestingly, the similar patterns were observed after the recent long-term experiment, where micrometer-thick deposits were observed at the bottom of the gap between ALT tiles [11]. All these findings called for the significant re-assessment of the existing modeling algorithms. I'm awaiting the newest results from Garching about NRA measurements at the bottom. Therefore, the numbers are subject to change, AL.

\section{Modeling of the deposition in the gaps}

In the earlier studies it was noted that simple processes of particle reflection from the gap walls might satisfactorily reproduce experimental deposition patterns. With the new findings such as deposition at the bottom of the gaps, it became clear that the modeling algorithms must be improved in order to match the experimental data. For this purpose a new 3D program code was developed with different particle sources and the possibility to trace an angular dependence of the reflection coefficient for several impurity species independently. Neutral collisions in the gap can be taken into account in the new code. However, aforementioned necessary improvements did not lead to significantly better agreement with experimental data. Recently a simple treatment of chemical erosion processes together with the homogeneous surface mixing model was implemented in the code.

Current results are provided on figure 4 , where the deposition at the side surfaces of a gap and at its bottom is plotted similar to the experimental data provided on figure 1 . It can be 
seen that the new code do shows better agreement with experimental data, yet still qualitative and partial. Parametric studies are required, and important physics may still be missing.

\section{Summary and outlook}

Tungsten castellated limiter with the two shapes of the castellation was exposed in the SOL plasmas of TEXTOR. The aim of this investigation was to test the castellation shaping as a tool to mitigate the impurity transport and fuel accumulation in the gaps. The limiter was exposed under erosion-dominated conditions, nevertheless, there were deposition-dominated conditions in the gaps.

Analyses of the deposits revealed the significant tungsten intermixing: up to 70 at. \% was found intermixed in the deposited layers in the poloidal gaps. Metal intermixing will significantly decrease the efficiency of cleaning of gaps in ITER.

The quantification of the total carbon and deuterium amounts both in toroidal and poloidal gaps of both shapes was finished. A factor of 3 less deuterium was found in the gaps of shaped poloidal cells, than those of non-shaped ones. The same time, the difference in the carbon deposition was less pronounced, which calls for the further optimization of the shaping. Toroidal gaps contained comparable amount of carbon and deuterium and cannot be ignored from the total accounting of fuel inventory and impurity transport in the gaps. Gaps contain about $10 \%$ of the total amount of carbon and less than $0.01 \%$ of $\mathrm{D}$ impinging the castellation. Such a low trapping ratio for D may be described by the temperature excursions during exposures leading to the thermal desorption of the accumulated fuel.

Significant deposition was detected at the bottom of the gaps. Up to $14 \%$ of the total amount of carbon deposited on poloidal gaps was found at their bottom. The deposition patterns at the bottom of the gaps imply that the deposition may be largely driven by the neutral particles. 
Modeling effort on addressing the aforementioned results had been continued. Several new processes, such as 3D sources of particles in the gaps, angle-dependent reflection coefficient, neutral transport inside the gaps and simple mixing model of an interaction layer were introduced in the upgraded model along with chemical erosion processes. However, only partial and qualitative agreement with the experimental data achieved so far. This calls explicitly for the further improvements of algorithms. As the analyses of this experiment are largely finished, the future efforts will be primarily concentrated on the model development to describe and reproduce experimentally observed deposition patterns.

\section{Acknowledgments}

The authors would like to thank sincerely M. Freisinger, H. Reimer, W. Müller and TEXTOR team for help and support. We are also grateful to Mrs. A. Stärk from the Central Department of Chemical Analyses of the Forschungszentrum Jülich for the SIMS data and to Mr. M. Spähn from RWTH Aachen for EPMA measurements. This work is being performed within the research program of the European Task Force on Plasma-Wall Interactions.

\section{References:}

1. K. Krieger, W. Jacob, D.L. Rudakov, R. Bastasz, G. Federici, A. Litnovsky, H. Maier, V. Rohde, G. Strohmayer, W.P. West, J. Whaley and C.P.C. Wong, J. Nucl. Mater., $363-365$ (2007) 870;

2. D. Rudakov, W. Jacob, K. Krieger, A. Litnovsky, V. Philipps, W. P. West, C. P. C. Wong, S. L. Allen, R. J. Bastasz, J. A. Boedo, N. H. Brooks, R. L. Boivin, G. De Temmerman, M. E. Fenstermacher, M. Groth, E. M. Hollmann, C. J. Lasnier, A. G. McLean, R. A. Moyer, P. C. Stangeby, W. R. Wampler, J. G. Watkins, P. Wienhold and J. Whaley Phys. Scr. T128 (2007) 29; 
3. M. Rubel, J. P. Coad, P. Wienhold, G. Matthews, V. Philipps, M. Stamp and T. Tanabe, Phys. Scripta T111 (2004), 112;

4. A. Litnovsky, V. Philipps, P. Wienhold, G. Sergienko, B. Emmoth, M. Rubel, U. Breuer and E. Wessel, J. Nucl. Mater. 337-339 (2002) 917;

5. A. Litnovsky, V. Philipps, P. Wienhold, G. Sergienko, A. Kreter, O. Schmitz, U. Samm, P. Karduck, M. Blome, B. Emmoth and M. Rubel Proc.of $32^{\text {nd }}$ EPS Conf. ECA Vol.29C (2005) P-1.015;

6. A. Litnovsky, V. Philipps, A. Kirschner, P. Wienhold, G. Sergienko, A. Kreter, U. Samm, O. Schmitz, K. Krieger, P. Karduck, M. Blome, B. Emmoth, M. Rubel, U. Breuer and A. Scholl, J. Nucl. Mater., 367-370 (2007) 1481;

7. G. Sergienko, B. Bazylev, A. Huber, A. Kreter, A. Litnovsky, M. Rubel, V. Philipps, A. Pospieszczyk, Ph. Mertens, U. Samm, B. Schweer, O. Schmitz and M. Tokar, J. Nucl. Mater., 363-365 (2007) 96;

8. A. Litnovsky, V. Philipps, P. Wienhold, K. Krieger, G. Sergienko, A. Kreter, O. Schmitz, U. Samm, Ph. Mertens, A. Kirschner, S. Droste, S. Richter, U. Breuer, A. Scholl, A. Besmehn and Y. Xu, Phys. Scr. T128 (2007) 45;

9. A. Litnovsky, V. Philipps, P. Wienhold, K. Krieger, A. Kirschner, D. Borodin, G. Sergienko, O. Schmitz, A. Kreter, U. Samm and TEXTOR Team, S.Richter and U. Breuer, J. Nucl. Mater. in press.

10. B. Schweer, S. Brezinsek, H.G. Esser, A. Huber, Ph. Mertens, S. Musso, V. Philipps, A. Pospieszczyk, U. Samm, G. Sergienko and P. Wienhold, Fus. Sci. and Technology, Vol. 47, Nr. 2 (2005) 138;

11. A. Kreter, P. Wienhold, H. G. Esser, A. Litnovsky, V. Philipps, U. Breuer, S. Richter, K. Sugiyama, talk at the 10th meeting of the ITPA TG on Div. and SOL, Avila, Spain, January 2008. 


\section{Figures:}

Figure 1: A view of a castellated limiter III after exposure with a nomenclature of cells (a), the geometry of cells (b) and the scheme of exposure (c).

Figure 2. Quantified metal mixing in the deposited layers formed in poloidal gap of the rectangular cell (er12b). The numbers show the atomic percentage of the tungsten in the deposit.

Figure 3: a) Distribution of areal deuterium and carbon atom density along the depth of poloidal gap of the rectangular (er12a) and shaped (is12a) cells: 1) Carbon atom density distribution along the gap of rectangular cell er12a; 2) Deuterium atom density distribution along the gap of rectangular cell er12a; 3) Carbon atom density distribution along the gap of shaped cell is12a; 4) Deuterium atom density distribution along the gap of shaped cell is12a. Arrows show the direction of the line scan along the gap.

b) The gap geometry: A- plasma open side of the gap with respect to the impinging plasma flow, B- plasma shadowed side. The edge of the shaped cell is shown with a dashed line.

Figure 4: Deposition at the bottom of the gaps: a view of the holder plate, measurement locations and deposit thickness as measured with SIMS/DEKTAK techniques.

Figure 5. Modeling of impurity transport and fuel accumulation in the gaps: a reconstructed deposition pattern on the poloidal gap obtained using a new algorithm.

Table 1. Total amount of $\mathrm{D}$ and $\mathrm{C}$ deposited on the poloidal and toroidal sides of gaps for both studied geometries: a) for poloidal gaps; b) for toroidal gaps and c) comparison of the total amount of carbon and deuterium in the poloidal and toroidal gaps. 


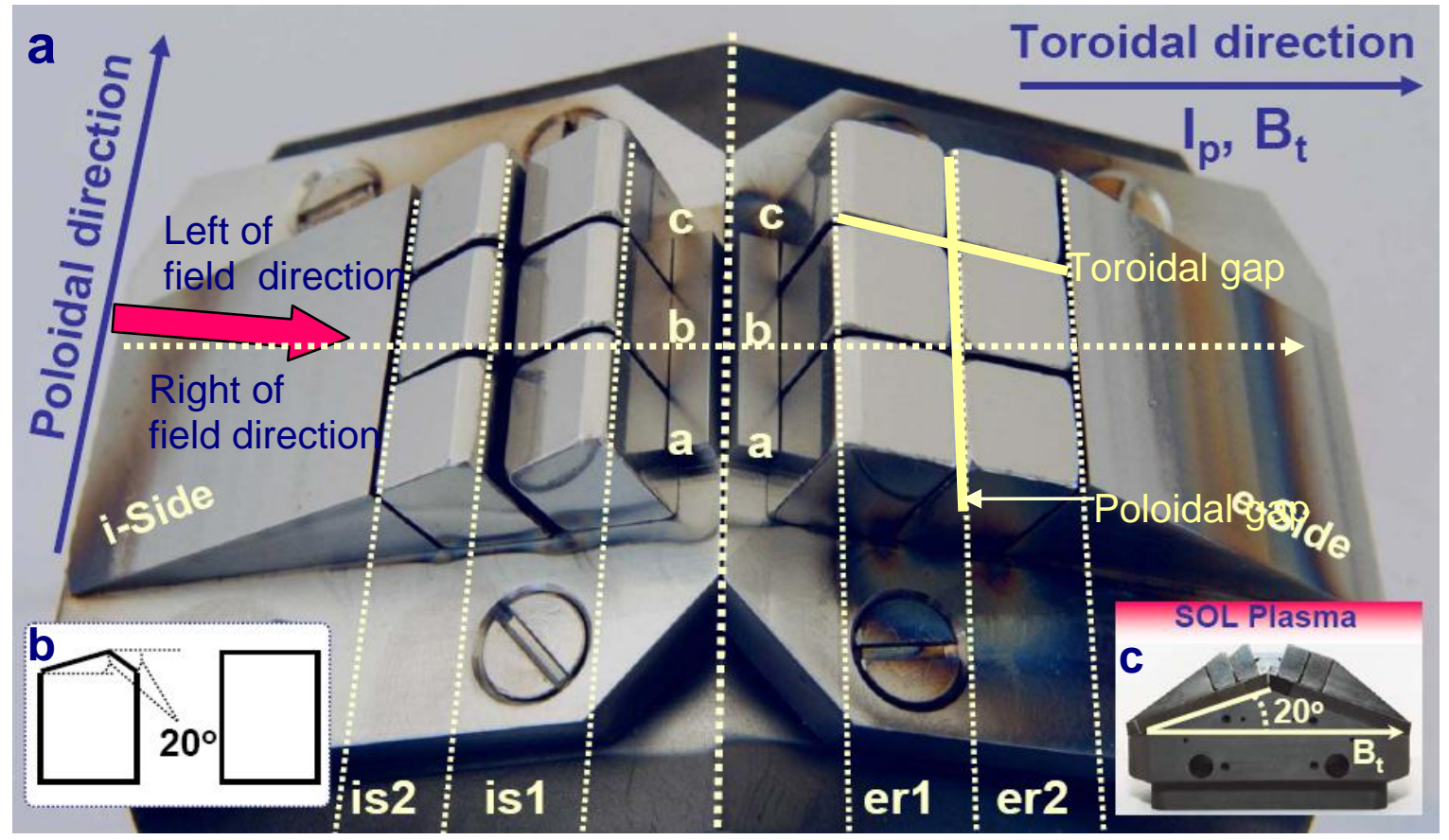

Figure 1: A view of a castellated limiter III after exposure with a nomenclature of cells (a), the geometry of cells (b) and the scheme of exposure (c). 


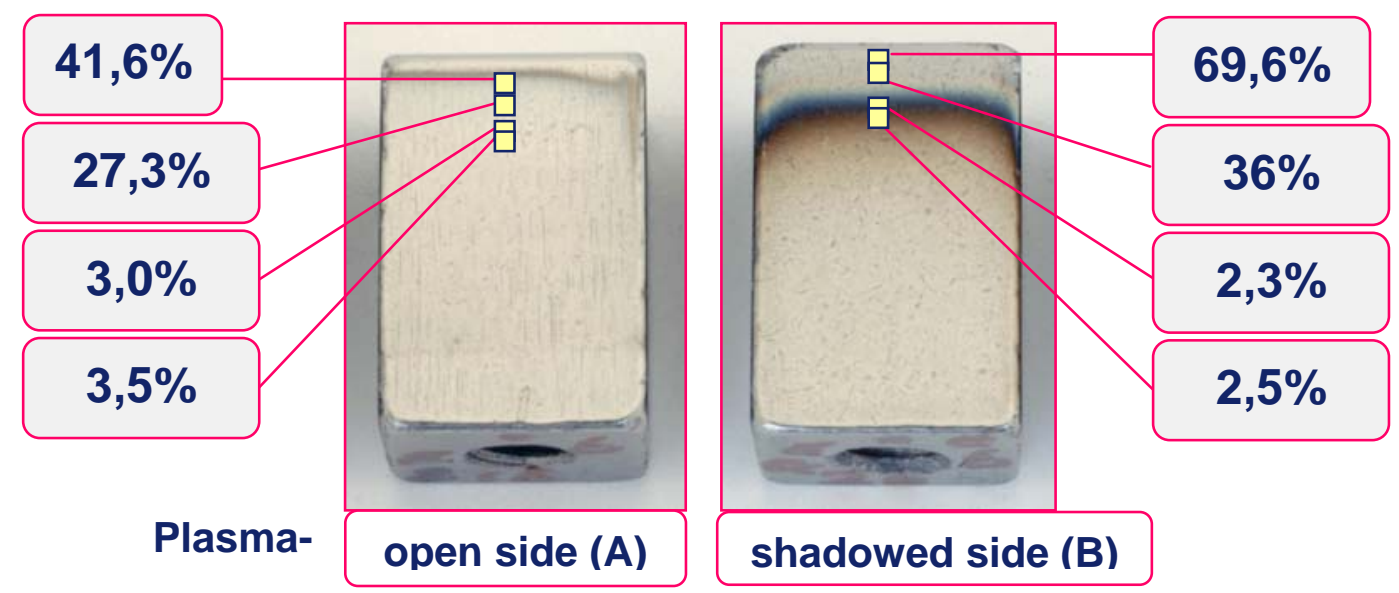

Figure 2. Quantified metal mixing in the deposited layers formed in poloidal gap of the rectangular cell (er12b). The numbers show the atomic percentage of the tungsten in the deposit. 


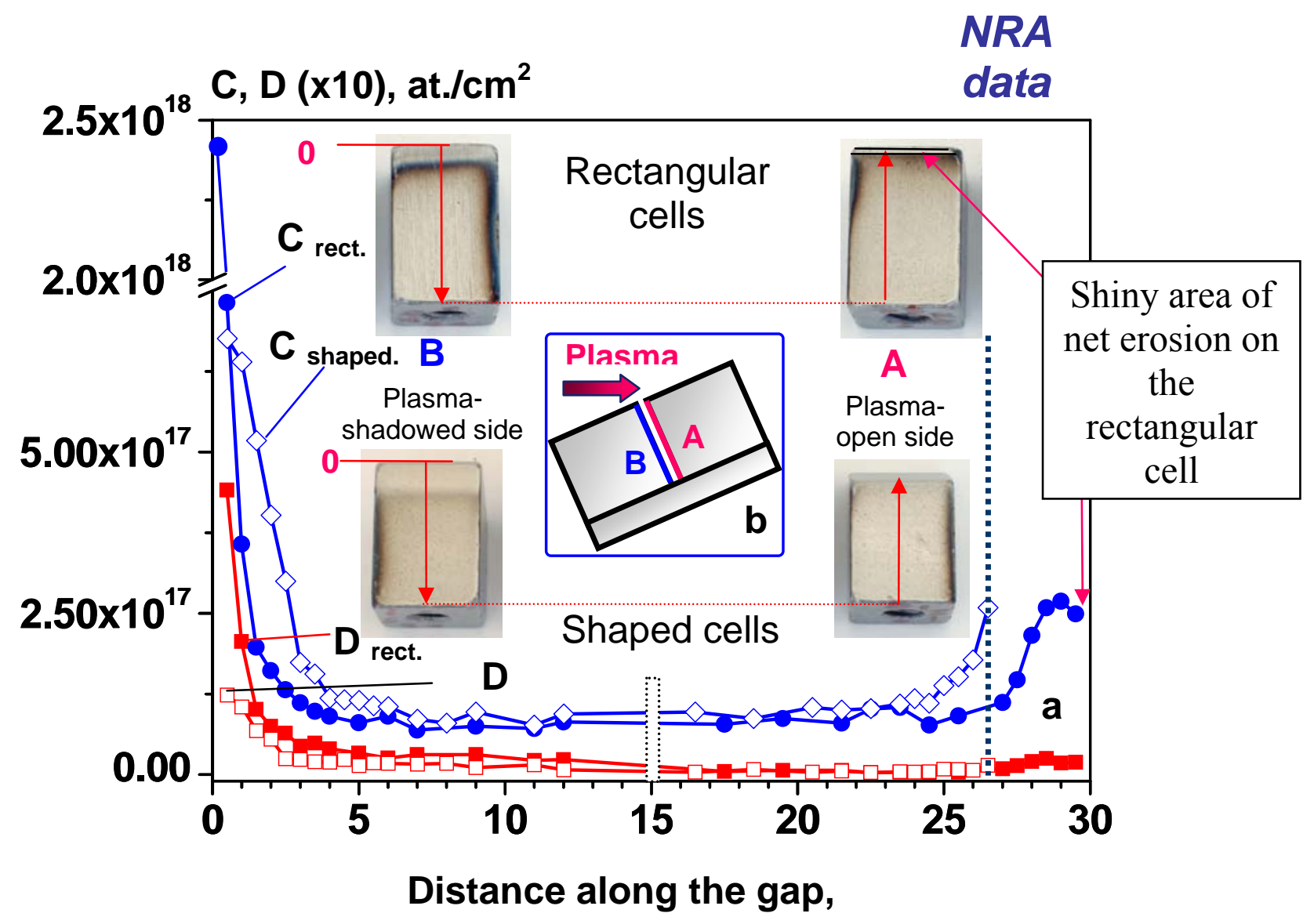

Figure 3: a) Distribution of areal deuterium and carbon atom density along the depth of poloidal gap of the rectangular (er12a) and shaped (is12a) cells: 1) Carbon atom density distribution along the gap of rectangular cell er12a; 2) Deuterium atom density distribution along the gap of rectangular cell er12a; 3) Carbon atom density distribution along the gap of shaped cell is12a; 4) Deuterium atom density distribution along the gap of shaped cell is12a. Arrows show the direction of the line scan along the gap.

b) The gap geometry: A- plasma open side of the gap with respect to the impinging plasma flow, B- plasma shadowed side. The edge of the shaped cell is shown with a dashed line. 


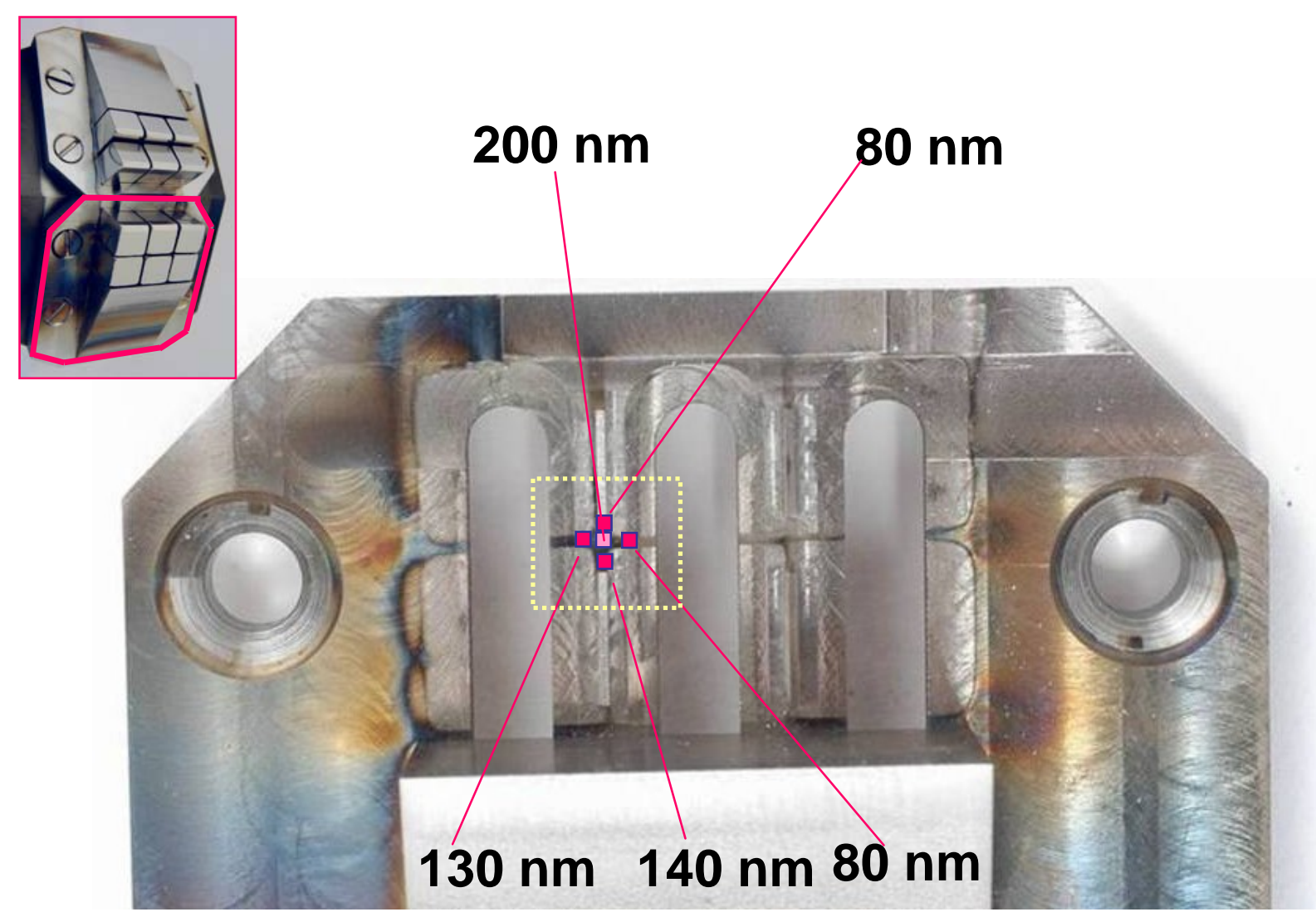

Figure 4: Deposition at the bottom of the gaps: a view of the holder plate, measurement locations and deposit thickness as measured with SIMS/DEKTAK techniques. 


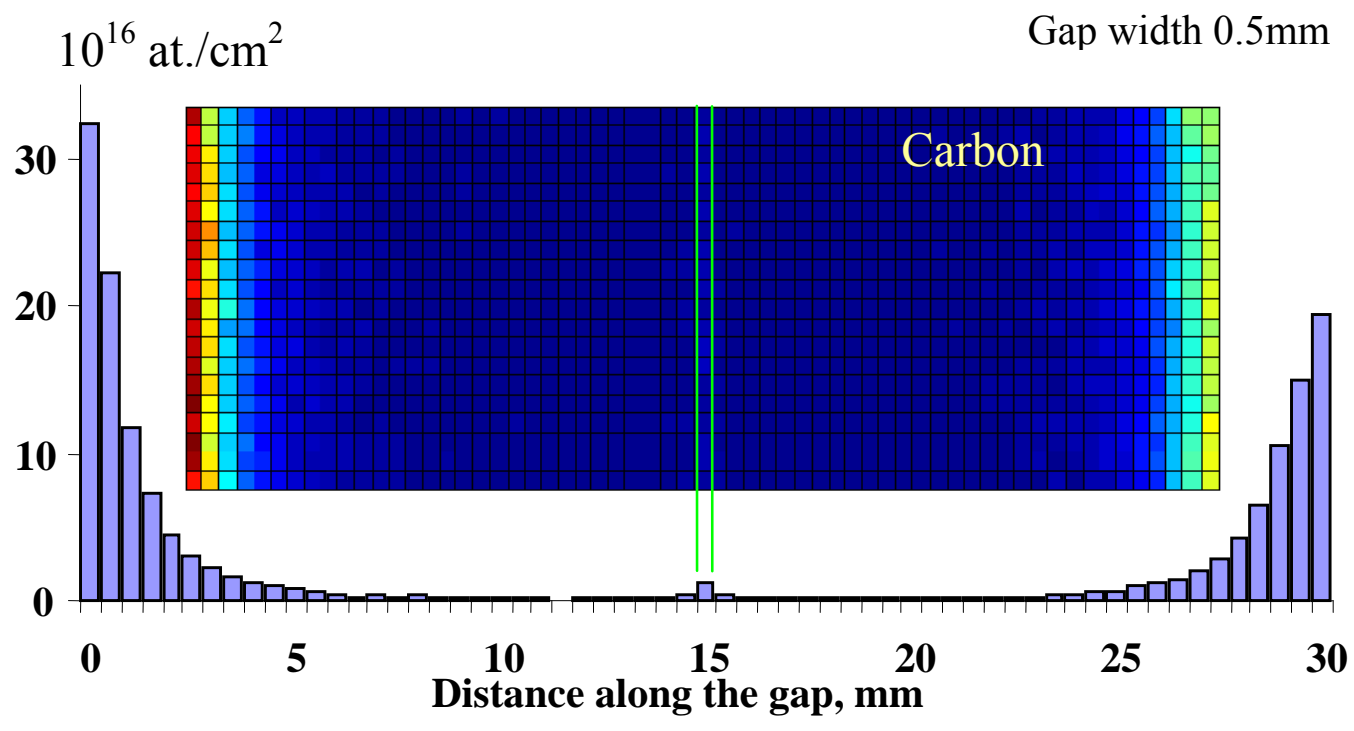

Figure 5. Modeling of impurity transport and fuel accumulation in the gaps: a reconstructed deposition pattern on the poloidal gap obtained using a new algorithm. 
Table 1.

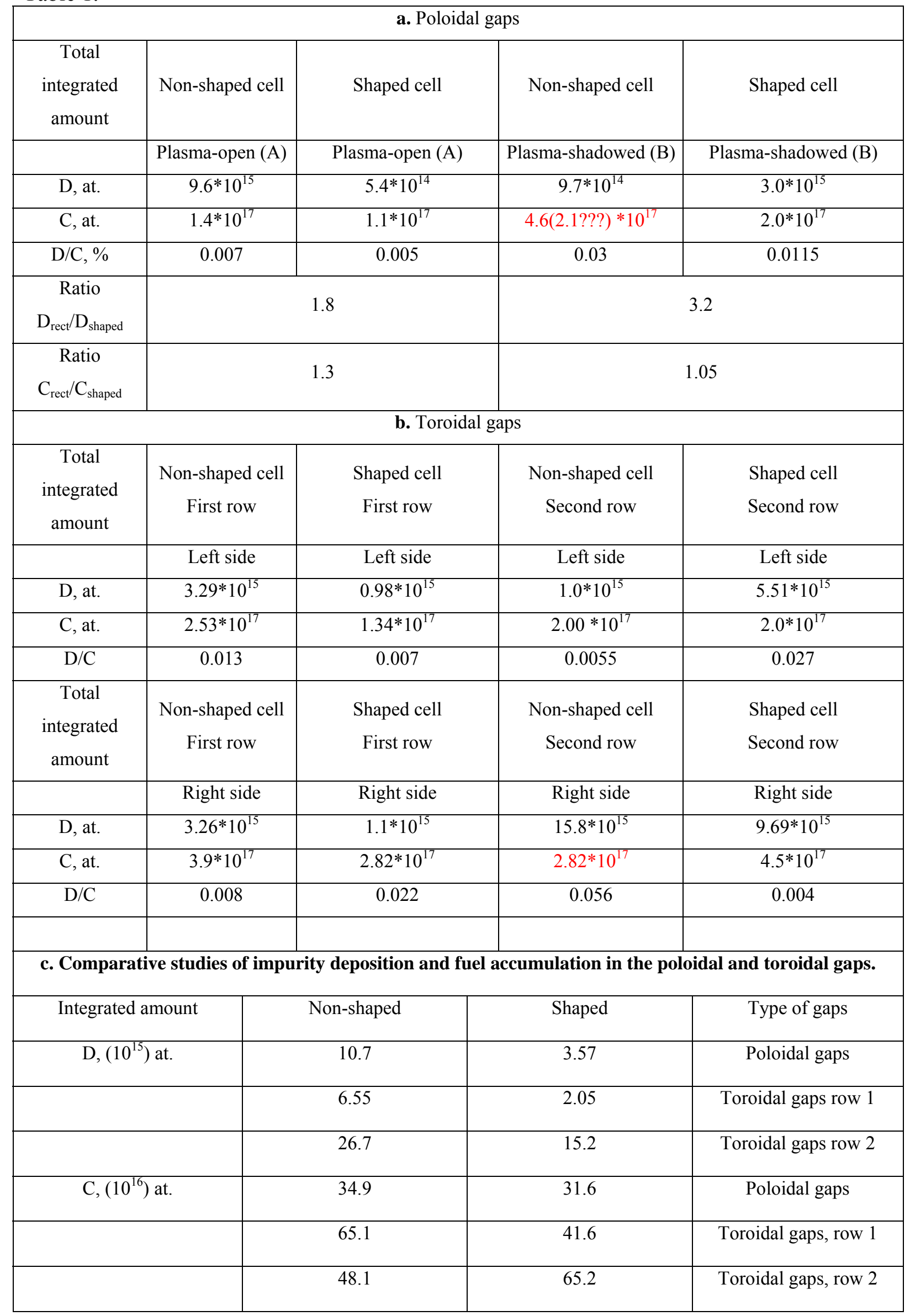


Table 1. Total amount of $\mathrm{D}$ and $\mathrm{C}$ deposited on the poloidal and toroidal sides of gaps for both studied geometries: a) for poloidal gaps; b) for toroidal gaps and c) comparison of the total amount of carbon and deuterium in the poloidal and toroidal gaps. 